\title{
Growth Trajectories of Extremely Low Birth Weight Infants From Birth to Young Adulthood: A Longitudinal, Population-Based Study
}

\author{
SAROJ SAIGAL, BARBARA STOSKOPF, DAVID STREINER, NIGEL PANETH, JANET PINELLI, AND MICHAEL BOYLE
}

Department of Pediatrics [S.S., B.S., J.P.], Department of Psychiatry and Neurosciences [M.B.], School of Nursing [J.P.], McMaster

University, Hamilton, Ontario, L8N 3Z5, Canada, Department of Psychiatry [D.S.], University of Toronto, Toronto, Ontario, M6A 2E1,

Canada; Departments of Epidemiology and Human Development [N.P.], Michigan State University, East Lansing, Michigan, 48823

\begin{abstract}
We compared sex-specific growth attainment of a population-based cohort of 147/166 (89\%) extremely low birthweight (ELBW $<1000 \mathrm{~g}$ ) and 131/145 (90\%) sociodemographically comparable normal birthweight (NBW) cohort at young adulthood, and examined the pattern of growth trajectories and correlates of growth at ages $1,2,3$, and $8 \mathrm{y}$, and teen and young adulthood (mean age, 23.3 versus $23.6 \mathrm{y}$ ). The proportion considered small for gestational age was ELBW $25 \%$ versus NBW $3 \%$; and $26 \%$ versus $2 \%$ had neurosensory impairments. Weight for age z-scores for ELBW showed substantial decline to age $3 \mathrm{y}$, with subsequent significant catch-up to adolescence and smaller gains to adulthood. Height for age z-scores showed both sexes of ELBW were disadvantaged at every age compared with NBW and their expected mid-parental height. The BMI z-scores for ELBW showed a sustained incline from age 3 to adulthood, where both sexes normalized to above zero, and were comparable to their peers. ELBW children showed growth failure during infancy, followed by accelerated weight gain and crossing of BMI percentiles at adolescence, a pattern that may increase the risk of insulin resistance and coronary heart disease. However, normalization of BMI for both sexes at adulthood suggests that final growth was proportionate. (Pediatr Res 60: 751-758, 2006)
\end{abstract}

Ceveral studies have shown that infants born with VLBW N $(<1500 \mathrm{~g})$ have significantly lower growth attainment in early and mid-childhood than their normal birth weight peers (1-3). Further follow-up to adolescence has shown that, although there was some catch-up, these children continued to be of smaller size (4-6). Growth data beyond adolescence are sparse (7-9). Recently, Hack et al. (8) published a longitudinal study on the growth of VLBW and term controls to age $20 \mathrm{y}$. To date, there is only one report on the growth of ELBW $(<1000 \mathrm{~g})$ infants at YA (10).

In this report, we present growth outcomes of a populationbased cohort of ELBW survivors followed longitudinally to YA. We will illustrate their sex-specific growth trajectories

Received April 25, 2006; accepted July 4, 2006.

Correspondence: Saroj Saigal, M.D., F.R.C.P.C., McMaster University, Department of Pediatrics, 1200 Main Street W., Room 4G40, Hamilton, ON, L8N 3Z5, Canada; e-mail: saigal@mcmaster.ca

This study was supported by grants MOP42536 from the Canadian Institutes of Health Research and 1 RO1 HD40219 from the National Institute of Child Health and Human Development.

DOI: 10.1203/01.pdr.0000246201.93662.8e from birth to adulthood in comparison to a reference group of term-born, NBW peers, and examine predetermined correlates of final growth attainment. We hypothesized that growth attainment of ELBW young adults would be lower than their NBW counterparts, and the pattern of growth trajectories would be different, with more rapid acceleration in growth by the ELBW cohort.

\section{METHODS}

Participants. Between 1977 and 1982, 179 of 397 (45\%) ELBW livebirths, 501-1000 g birth weight, born to residents of a geographically defined region in central-west Ontario, survived to hospital discharge and were followed longitudinally from birth (11).

At age 8 y, 145 term-born NBW children, comparable in sex, age, and social class (12) to the ELBW group (13), were recruited from a random list provided by local school boards and followed longitudinally.

Assessment protocol. Parents completed a questionnaire regarding their current sociodemographics. The young adults were interviewed by masked interviewers regarding their demographics (14) and health status using the SF-36 (15), a well-validated questionnaire that measures eight multidimensions of health experienced by the respondent in the last month, and provides norm-based summary scores for physical and mental health. Anthropometric measurements were recorded by trained research staff who were not blind to the group status. The assessments were conducted at McMaster Children's Hospital between January 1, 2002, and April 30, 2004.

Standing height, weight, and head circumference were obtained using standardized techniques. Height was measured without shoes using a balance beam scale with height rod while maintaining correct posture. Weight was obtained on a calibrated scale without shoes but wearing light clothing. Occipitofrontal head circumference was measured using a paper tape. Measurements were taken twice and a mean reading was recorded.

Longitudinal growth data were collected prospectively for ELBW subjects at birth, 1, 2, and 3 y corrected age, and at 8 y (13), teen (11-16 y) (6), and YA (21.5-26.5 y) unadjusted age. Kramer et al. (16) weight for gestational age data were used as they allow calculation of sex-specific z-scores at birth; SGA was defined as $<10$ th percentile. Comparable data for NBW cohort were obtained only at age $8 \mathrm{y}$, teen, and YA. Data on height and weight measures were converted to z-scores [(observed height or weight - mean height or weight)/SD], using EPI-Info software from the Revised Center for Disease Control (CDC) web site 2000 standards (17). The upper limit of CDC reference norms up to $20 \mathrm{y}$ of age were considered to be representative of adult growth attainment. Occipitofrontal head circumference was plotted on the sex-specific Nelhaus head circumference growth chart using age 18 as the reference point (18). Body mass index (BMI) was calculated by the relation of body weight to height squared (weight $\mathrm{kg} /$ height $\mathrm{m}^{2}$ ), using EPI-Info software. Data at all ages are also reported as proportion $\geq 2 \mathrm{SD}$ below the mean for all measurements.

Abbreviations: ELBW, extremely low birth weight; NSI, neurosensory impairments; SGA, small for gestational age; VLBW, very low birth weight; YA, young adulthood 
Correlates examined for their relationship with growth were selected from the literature $(4,8)$, and included the following individual factors: birth weight group, SGA, gender, NSI, chronic health conditions at adolescence, and age at menarche among females. Total days in hospital, days to regain birth weight, and prenatal steroids were considered for the ELBW cohort only. Family factors were mid-parental height and parental social class (at age $8 \mathrm{y})$.

The study was approved by the Research Ethics Board of Hamilton Health Sciences. Written informed consent was obtained from all participants.

Statistical analyses. Chi-square tests of significance were used to assess differences in categorical variables between ELBW and NBW subjects; ANOVA was used to compare mean differences between groups, and $95 \%$ confidence intervals were computed.

A hierarchical regression was used to test for significant correlates of the following outcome variables at YA: height, weight, BMI z-scores, and head circumference. A temporally ordered five-step model was used-step 1: sex, mid-parental height, and social class (12), known to be highly correlated with growth; step 2: birthweight group (ELBW, NBW); step 3: SGA (16); step 4: NSI; and step 5: chronic health conditions at teen (sum of number of problems). Age at menarche was added to the final step for females. In another separate analysis of the ELBW group alone, three additional variables were added to the model after step 3 (total number of days in hospital, days to regain birthweight, and prenatal steroids).

We also used linear growth curve analysis (19) and the statistical software MLwiN (20) to model and compare growth trajectories for standardized height, weight, and BMI for ELBW versus NBW participants at age $8 \mathrm{y}$, teen, and adulthood. In growth curve analysis, individual observations are regressed on time to estimate two parameters for each person - an average value at a selected point in time (intercept) and a regression coefficient estimating the change in response per unit time. These two parameters provide the basis for between-subject comparisons in average levels and rates of growth. In our analysis, time was measured in yearly increments and the intercept was set at $23 \mathrm{y}$ to compare the groups as young adults.

SPSS version 11.0 (SPSS Inc., Chicago, IL) was used for all statistical analyses. Although exact $p$ values $<0.05$ are provided where applicable, due to multiple testing, Holm's correction (21) was used for key variables of primary hypotheses to establish statistical significance.

\section{RESULTS}

ELBW participants. Of 179 survivors, 13 children subsequently died; 9 were lost ( 2 had neurosensory impairments, NSI), 8 declined to participate (4 NSI), and 2 YA with severe
NSI were unable to be measured. The outcome is reported on 147/166 (89\%) long-term survivors.

Birth demographics. Mean birthweight and gestational age of ELBW participants was $841 \mathrm{~g}$ and $27.1 \mathrm{wk}$, respectively; $22 \%$ were $<26$ wk GA and $25 \%$ were SGA (16) (Table 1 ). It is apparent from the high proportion of ELBW who were ventilated and the prolonged neonatal hospitalization that this cohort experienced significant neonatal morbidity. None of the subjects received postnatal steroids.

Early nutrition. The majority of infants received parenteral alimentation-i.v. amino acid: 93\% (mean duration: $24.8 \mathrm{~d}$ ) and i.v. intralipid: $76 \%$ (mean duration: 23.8 d). Expressed breast milk was offered rarely. The practice in that era was to feed concentrated formula (SMA24, SMA30 calories/oz) to ensure adequate caloric intake. Nevertheless, mean days for the infants to regain their birth weight was 24.0 (SD 10.8).

Current demographics. NSI were identified in $26 \%$ of ELBW YA. There were no differences in parental demographic and neonatal variables between participantsand nonparticipants. The mean age of participants was 23.3 (SD 1.2) unadjusted years.

NBW participants. At YA, 5 subjects were lost, 9 refused, and 131/145 (90\%) YA participated. Mean birth weight was 3380 (SD 475) g; 3\% were SGA and 2\% had NSI. There were no differences in sociodemographic and neonatal variables between participants and nonparticipants. Mean age at assessment was of 23.6 (SD 1.1) y.

Comparison of ELBW and NBW participants. At YA, there were significant differences in the proportion with NSI ( $26 \%$ versus $2 \%, p<0.001)$ (Table 2 ). Current health status (SF36) (15) for both groups and mean age at menarche for ELBW and NBW females were similar. The majority of subjects were Caucasian.

Table 1. Birth demographics and neonatal morbidity of ELBW cohort by sex

\begin{tabular}{|c|c|c|c|}
\hline & $\begin{array}{c}\text { Males } \\
(n=65)\end{array}$ & $\begin{array}{l}\text { Females } \\
(n=82)\end{array}$ & $\begin{array}{c}\text { Total } \\
(n=147)\end{array}$ \\
\hline Gestation, wk, mean (SD) & $27.0(2.4)$ & $27.2(2.2)$ & $27.1(2.3)$ \\
\hline Birth weight, g, mean (SD) & $844(112)$ & $838(135)$ & $841(125)$ \\
\hline Gestation $<26$ wks, $n(\%)$ & $15(23)$ & $18(22)$ & $33(22)$ \\
\hline SGA, $<10$ th percentile $(16), n(\%)$ & $13(20)$ & $23(28)$ & $36(25)$ \\
\hline Singleton, $n(\%)$ & $64(99)$ & $76(93)$ & $140(95)$ \\
\hline Duration in days, $\ddagger$ mean (SD) & $37.8(25.5)$ & $34.6(27.3)$ & $36.0(26.5)$ \\
\hline Chronic lung disease, $\S n(\%)$ & $35(54)$ & $33(40)$ & $68(46)$ \\
\hline \multicolumn{4}{|l|}{ Neonatal nutrition: } \\
\hline i.v. amino acid, $n(\%)$ & $62(95)$ & $75(91)$ & $137(93)$ \\
\hline Mean duration, d (SD) & $24.2(18.7)$ & $25.4(23.0)$ & $24.8(21.1)$ \\
\hline i.v. intralipid, $n(\%)$ & $52(80)$ & $59(72)$ & $111(76)$ \\
\hline Median (range) & $95.5(49-175)$ & $95(27-193)$ & $95(27-193)$ \\
\hline
\end{tabular}

All $\chi^{2}$ and $t$ tests are not significant.

$\ddagger$ Includes positive pressure ventilation only; excludes continuous positive airway pressure.

$\S$ Chronic lung disease defined as oxygen dependency $>28 \mathrm{~d}$ of age.

If Data collected for 1979-1982 births only $(n=88)$. 
Table 2. Current demographics by sex of ELBW and NBW young adults

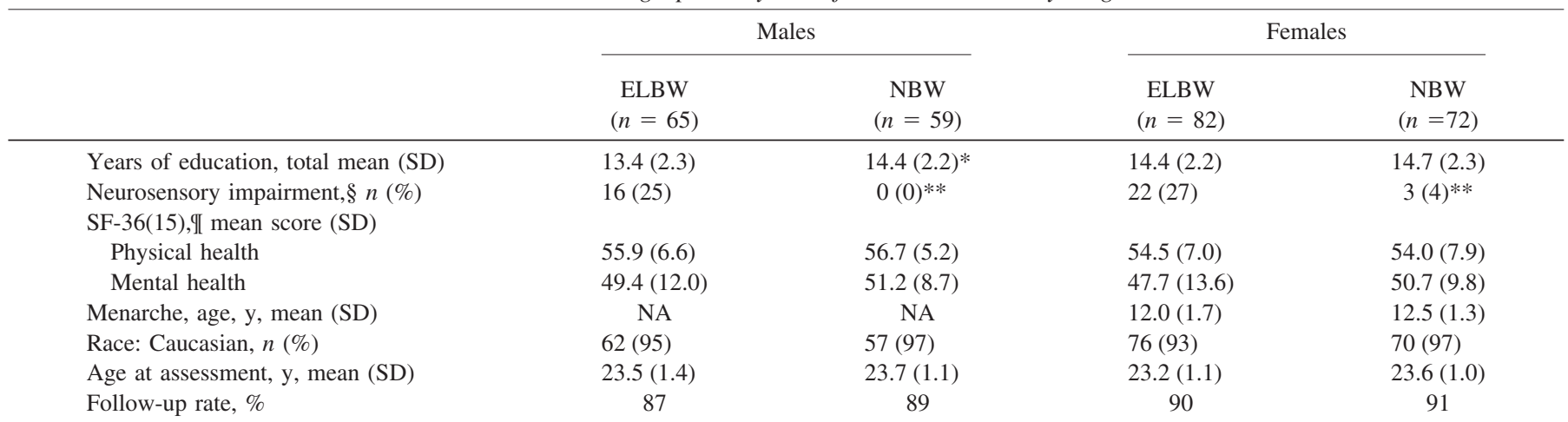

$\S$ NSI included ELBW: cerebral palsy $(n=20)$, hydrocephalus $(n=6)$, microcephaly $(n=1)$, mental retardation $(n=10)$, unilateral blindness $(n=8)$, bilateral blindness $(n=11)$, not mutually exclusive; NBW: cerebral palsy $(n=1)$, mental retardation $(n=1)$, unilateral deafness $(n=1)$.

$* p=0.01 ; \quad * * p<0.001$.

If Norm-based: mean $=50($ SD 10); all comparisons were nonsignificant.

Parental demographics. At delivery, mothers of ELBW infants were significantly younger than the NBW group (25.9 versus $28.6 \mathrm{y}, p<0.001$ ) (Table 3). Other information on maternal demographics, smoking, and hypertension was available only for the ELBW cohort. Antenatal steroids were administered to $47 \%$ of mothers. There were no differences in the current sociodemographics between the two groups, or in the self-reported height and weight measurements of the biologic parents (6).

Weight. At birth, z-scores for male and female ELBW participants were significantly below zero $(-0.73$ and -0.70 , respectively) (Table 4 and Fig. 1). These scores decreased precipitously between birth and age 1 y (by -1.76 in males versus -1.26 in females), then increased substantially to age $3 \mathrm{y}$. By age $8 \mathrm{y}$, the weight z-scores of both sexes of ELBW were similar $(-1.05)$. Subsequent growth among ELBW males was steady, but ELBW females exhibited a sharper incline between ages 8 and $14 \mathrm{y}$. At every age, the weight z-scores of both sexes of ELBW were below zero (50th percentile), and significantly lower than NBW who were consistently above zero. Between ages 8 and 23, the graphs exhibit some convergence in weight z-scores between the two groups: NBW participants reached a plateau at age 14, whereas ELBW participants continued to make small gains in z-scores to adulthood.

In terms of final adult weight (Table 5), ELBW males were $6.5 \mathrm{~kg}$ lighter [95\% confidence interval (CI), $-11.7,-1.2$; $p=0.01]$, and ELBW females were $7.1 \mathrm{~kg}$ lighter $(95 \% \mathrm{CI}$, $-11.8,2.4 ; p=0.003$ ) than their NBW counterparts. Therewere no differences in the proportion who were $\leq-2 \mathrm{SD}$ below the mean for weight among males (ELBW $11 \%$ versus NBW $3.4 \%, p=0.20$ ); however, there were differences among females (ELBW $8.5 \%$ versus NBW 1.4\%, $p<0.05$ ).

Height. The mean birth length for ELBW infants was 34.2 $\mathrm{cm}$ for males and $34.4 \mathrm{~cm}$ for females (Table 4; reference length $\mathrm{z}$-scores at birth were unavailable) (16). At age $1 \mathrm{y}$, length z-scores for ELBW were -1.59 for males and -1.04 for females (Fig. 1). Both sexes of ELBW showed a gradual increase in mean height $\mathrm{z}$-score from age 2 to adolescence (except at age $8 \mathrm{y}$ ). The increment in height $\mathrm{z}$-scores between age 8 and adolescence by ELBW was not as remarkable as their concurrent increase in weight z-scores. Both sexes of NBW were just below zero for height z-score at age 8 and showed significant gains by adolescence, which leveled off at adulthood.

At adulthood (Table 5), ELBW males were $7.2 \mathrm{~cm}$ shorter (95\% CI, $-10.3,-4.1, p<0.001)$, and ELBW females were $6.2 \mathrm{~cm}$ shorter $(95 \% \mathrm{CI},-8.3,-4.0, p<0.001)$ than their NBW peers. A higher proportion of ELBW males versus NBW males was $\leq-2$ SD below mean for adult height $(15.0 \%$ versus $1.7 \%, p<0.01)$; females did not differ significantly.

Head circumference. Reference standards for head circumference z-scores by gestational age at birth and beyond age $3 \mathrm{y}$

Table 3. Parental demographics on ELBW and NBW participants

\begin{tabular}{|c|c|c|}
\hline & $\begin{array}{c}\text { ELBW } \\
(n=143)\end{array}$ & $\begin{array}{c}\text { NBW } \\
(n=126)\end{array}$ \\
\hline \multicolumn{3}{|l|}{ Maternal demographics around delivery } \\
\hline Maternal age, y, mean (SD) & $25.9(5.4)$ & $28.6(5.0)^{*}$ \\
\hline Maternal smoking, $\% \%$ & 30 & NA \\
\hline Maternal hypertension, , $\%$ & 15 & NA \\
\hline Antenatal steroids, full course, $\%$ & 29 & NA \\
\hline Antenatal steroids, incomplete course, $\%$ & 18 & NA \\
\hline \multicolumn{3}{|l|}{ Current demographics } \\
\hline \multicolumn{3}{|l|}{ Maternal education, $n(\%)$} \\
\hline$<$ High school & $32(22)$ & $26(21)$ \\
\hline High school & $45(32)$ & $27(21)$ \\
\hline$>$ High school & $66(46)$ & $73(58)$ \\
\hline \multicolumn{3}{|l|}{ Social class $(12), n(\%)$} \\
\hline I, II & $67(47)$ & $70(56)$ \\
\hline III & $43(30)$ & $27(21)$ \\
\hline IV, V & $33(23)$ & $29(23)$ \\
\hline Two-parent families, $n(\%)$ & $117(82)$ & $101(80)$ \\
\hline \multicolumn{3}{|l|}{ Parental height and weight $\S$} \\
\hline \multicolumn{3}{|l|}{ Mothers $(\mathrm{ELBW}=119 ; \mathrm{NBW}=107)$} \\
\hline Weight, kg, mean (SD) & $66.4(13.2)$ & $66.9(12.7)$ \\
\hline Height, cm, mean (SD) & $163.7(7.1)$ & $164.5(7.1)$ \\
\hline \multicolumn{3}{|l|}{ Fathers $(\mathrm{ELBW}=126 ; \mathrm{NBW}=107)$} \\
\hline Weight, kg, mean (SD) & $83.3(12.7)$ & $80.2(11.8)$ \\
\hline Height, cm, mean (SD) & $176.6(6.8)$ & $176.6(7.6)$ \\
\hline
\end{tabular}


Table 4. Longitudinal sex-specific anthropometric measurements and z-scores§ of ELBW and NBWI participants, from birth to adolescence $\neq$

\begin{tabular}{|c|c|c|c|c|c|c|c|c|c|}
\hline & \multicolumn{3}{|c|}{ Weight (kg) } & \multicolumn{3}{|c|}{ Height $(\mathrm{cm})$} & \multicolumn{3}{|c|}{ Head circumference $(\mathrm{cm})$} \\
\hline & No. & Mean (SD) & Z-score (SD) & No. & Mean (SD) & Z-score (SD) & No. & Mean (SD) & Z-score (SD) \\
\hline \multicolumn{10}{|l|}{ Males } \\
\hline Birth (g) & 84 & $840(112)$ & $-0.73(.97)$ & 60 & $34.2(2.2)$ & N/A & 65 & $24.0(1.4)$ & N/A \\
\hline $1 \mathrm{y}$ & 74 & $7.7(1.3)$ & $-2.49(1.5)$ & 73 & $70.2(4.3)$ & $-1.59(1.5)$ & 74 & $45.3(1.8)$ & $-0.54(1.3)$ \\
\hline $2 y$ & 66 & $10.4(1.6)$ & $-1.90(1.4)$ & 64 & $82.9(4.2)$ & $-0.92(1.2)$ & 64 & $47.8(1.9)$ & $-0.51(1.3)$ \\
\hline ELBW & 67 & $22.5(4.7)$ & $-1.05(1.4)]$ & 67 & $121.7(7.8)$ & $-0.84(1.3)]$ & 67 & $51.5(1.5)$ & N/A \\
\hline NBW & 66 & $27.3(5.0)$ & $0.12(.90)]^{*}$ & 66 & $128.2(5.7)$ & $-0.06(.87)]^{*}$ & 66 & $53.3(1.4)]^{*}$ & N/A \\
\hline \multicolumn{10}{|l|}{ Teen } \\
\hline ELBW & 65 & $48.7(14.3)$ & $-0.53(1.5)]$ & 65 & $158.3(14.4)$ & $-0.46(1.5)]$ & 63 & $54.3(2.1)]$ & N/A \\
\hline NBW & 53 & $59.6(14.7)$ & $0.47(.89)]^{*}$ & 53 & $167.4(10.9)$ & $0.32(.97)]^{*}$ & 52 & $56.6(1.6)]^{*}$ & N/A \\
\hline \multicolumn{10}{|l|}{ Females } \\
\hline \multicolumn{10}{|l|}{ ELBW } \\
\hline $3 y$ & 64 & $12.2(1.7)$ & $-1.16(1.4)$ & 62 & 90.4 (4.6) & $-0.58(1.1)$ & 56 & $47.9(1.5)$ & $-0.30(.95)$ \\
\hline \multicolumn{10}{|l|}{$8 y$} \\
\hline ELBW & 80 & $21.9(3.4)$ & $-1.05(1.2)]$ & 80 & $120.9(6.1)$ & $-0.94(1.1)]$ & 80 & $50.6(1.4)$ & N/A \\
\hline NBW & 79 & $27.8(5.2)$ & $0.21(.96)]^{*}$ & 79 & $128.1(5.7)$ & $-0.01(.87)]^{*}$ & 79 & $52.7(1.5)]^{*}$ & N/A \\
\hline \multicolumn{10}{|l|}{ Teen } \\
\hline ELBW & 79 & $48.1(11.7)$ & $-0.24(1.0)$ & 79 & $154.2(7.5)$ & $-0.59(.92)]$ & 78 & $53.6(1.8)]$ & N/A \\
\hline NBW & 68 & $56.2(10.5)$ & $0.43(.84)]^{*}$ & 68 & $161.9(6.8)$ & $0.25(.95)]^{*}$ & 68 & $55.6(2.0)]^{*}$ & N/A \\
\hline
\end{tabular}

Mean ages (SD) at assessment-1 y: ELBW = 11 (1.7) mo CA; 2 y: ELBW = 23 (1.8) mo CA; 3 y: ELBW = 34 (2.0.) mo CA; 8 y: ELBW = 94 (5) mo; $\mathrm{NBW}=97$ (6) mo; teen: $\mathrm{ELBW}=14.1$ (1.6) y; NBW $=14.4$ (1.3) y.

$* p<0.001$, by Holm's correction.

If data available from age $8 \mathrm{y}$ only in the NBW cohort.

$\ddagger$ Corrected age (CA) until $3 \mathrm{y}$, and chronologic age at $8 \mathrm{y}$ and adolescence.

$\S \mathrm{CDC}$ web site, available at http://cdc.gov/nccdpho/dpna/growthcharts/sas.htm.

N/A, not available.

were unavailable. At ages 1, 2, and $3 \mathrm{y}$, head circumference z-scores improved for both sexes (Table 4). Mean head circumference measurements for male and female ELBW were significantly smaller than NBW group at both age 8 and teen ( $p<0.001$, by Holm's correction). At YA, the mean difference in head circumference was similar for both sexes (males, $-1.5 \mathrm{~cm}, 95 \% \mathrm{CI},-2.1,-0.90$; females, $-1.7 \mathrm{~cm}, 95 \% \mathrm{CI}$, $-2.3,-1.1, p<0.001$, by Holm's correction) (Table 5).

Comparison of height, weight, and BMI between YA/ parent dyads. Due to missing data, there were fewer YA/ parent dyads $(\mathrm{ELBW}=116 ; \mathrm{NBW}=103)$. The mean height and weight of both parent groups were within $2 \mathrm{~cm}$ and $2 \mathrm{~kg}$ of the 50th percentile, based on the Metropolitan Life Insurance Company Height and Weight Tables. ELBW YA were significantly shorter $(p<0.001)$ and lighter $(p=0.001)$, relative to their mid-parental height and weight (Table 6). The growth of NBW YA was consistent with their parental measures.

BMI. ELBW of both sexes showed a continuing catch-up in mean z-scores with crossing of percentiles (Fig. 1). This increase in z-scores was greater between age 8 y and adolescence for ELBW females, relative to ELBW males (0.73 versus 0.42 ). At adulthood, unlike height and weight $\mathrm{z}$-scores, mean BMI z-scores of both sexes of ELBW normalized to above zero (males, 0.05; females, 0.21), and were comparable to the NBW YA. The NBW cohorts were above zero at all ages. At adulthood, there were no differences between groups by gender in the proportion with BMI in the normal, overweight, or obese range ( $p=0.16$ for males, 0.14 for females).

Hierarchical regression analyses. Height $\mathrm{z}$-score was the outcome with the most variance explained by the five-step model. In the final model, $40.1 \%$ of the variance in height Z-score was explained; step 1 (SES, mid-parental height, gender) accounted for $21.3 \%$ of the total variance. Step 2 (BW group) added $16.4 \%$ of the explained variance, and there was very little subsequent improvement in variance explained by the additional steps (Table 7). In the final model, mid-parental height $(p<0.001)$, birth weight group $(p<$ $0.001)$, and NSI $(p=0.02)$ were significant; birth weight and NSI had a negative relationship with YA height. The addition of age at menarche (added at the final step) for females only, increased the variance explained from $34.6 \%$ to $36.6 \%$. The five-step model explained $38.7 \%$ of the variance for head circumference, $9.4 \%$ for weight $\mathrm{z}$-score, and $1.4 \%$ for BMI z-score. For each of these outcomes, Step 2 (BW group) accounted for almost all of the variance. Sex was a significant variable in the final model for head circumference only.

In another separate analysis of the ELBW cohort only (not shown), with height as the final outcome, the addition of days to regain birthweight, total days in hospital and prenatal steroids (after step 3) did not result in significantly more variance ex- 
Males
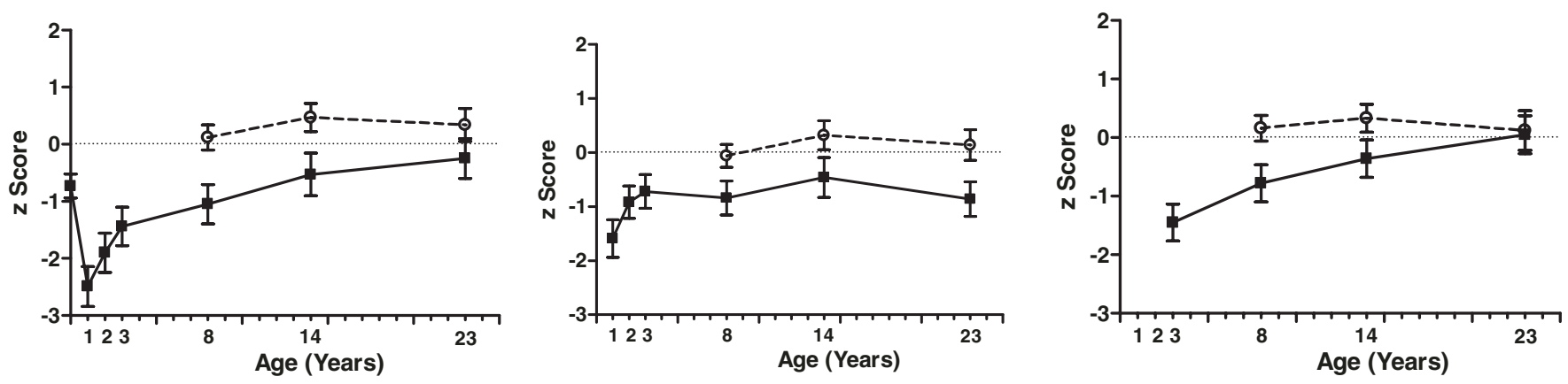

\section{Females}
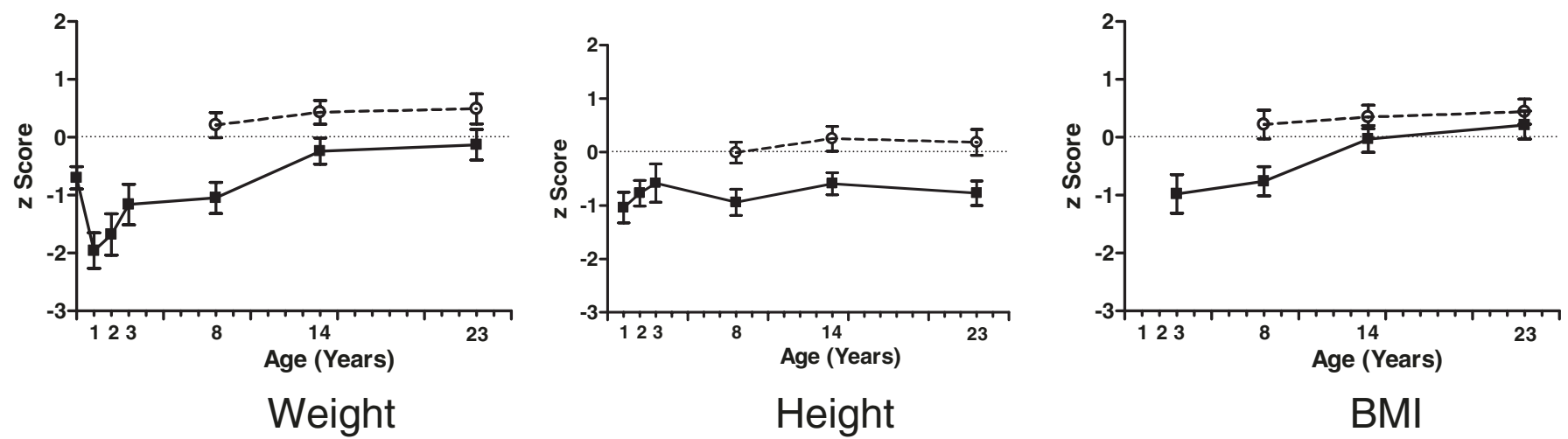

Figure 1. Mean height, weight, and BMI z-scores and 95\% CI for ELBW (ם) and NBW (O) subjects, from birth to adulthood.

Table 5. Sex-specific anthropometric measurements, z-scores, § and BMI of ELBWII and NBW cohorts at YA

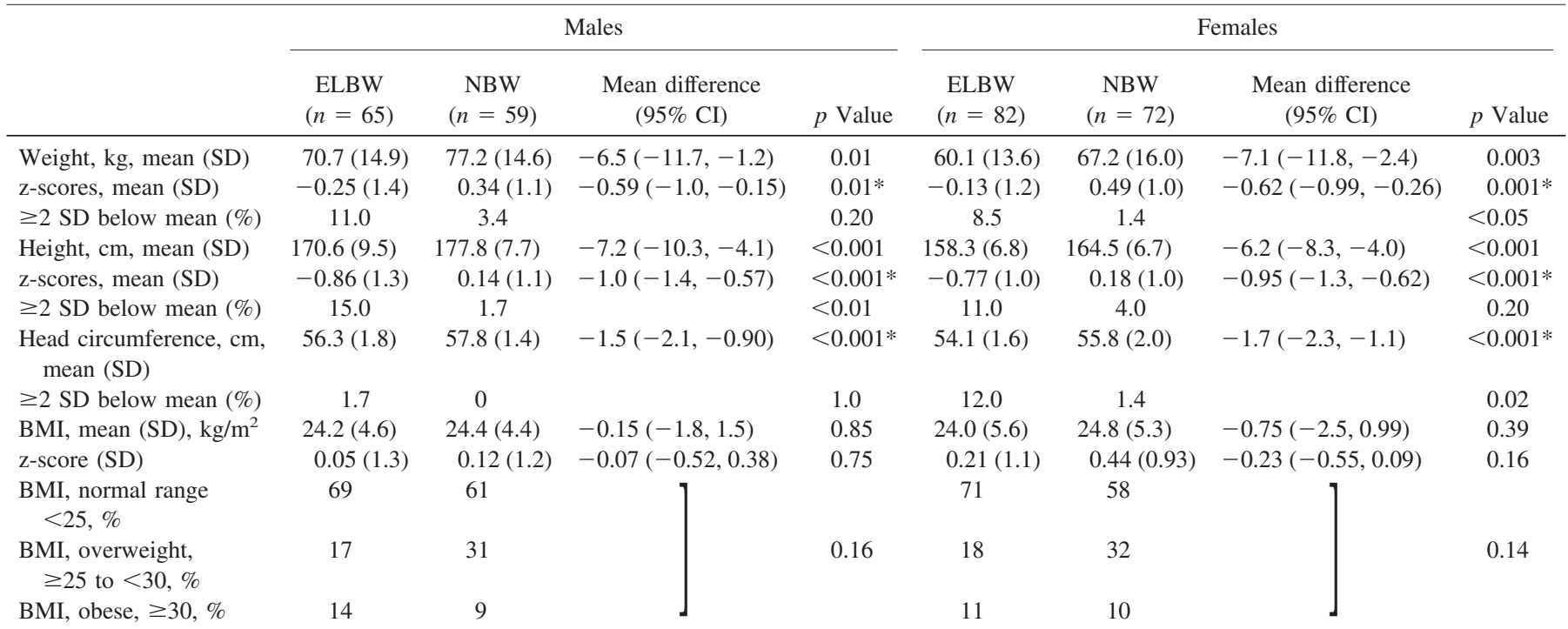

When NSI excluded-males: height z-scores remained significantly different between groups, $p<0.001$; females: both height and weight Z-cores remained significantly different, $p<0.001 ; p=0.003$, respectively.

* Significant by Holm's correction.

II Information on the growth parameters of five ELBW YA with NSI was obtained from their most recent visit to their physicians.

$\S$ CDC web site, available at http://cdc.gov/nccdpho/dpna/growthcharts/sas.htm.

plained $(22 \%, \mathrm{R}$ square $=0.334$, adjusted $\mathrm{R}$ square $=0.220$, from $20.5 \%$, $\mathrm{R}$ square $=0.247$, adjusted $\mathrm{R}$ square $=0.025$ ).

Linear growth curve analysis. At YA, standardized height and weight were significantly lower for ELBW versus NBW participants $(-0.896 \mathrm{SE}=0.130 ;-0.543, \mathrm{SE}=0.138)$, but not for standardized BMI $(-0.124, \mathrm{SE}=0.132)$. There was no statistically significant difference between ELBW and NBW participants in yearly changes in height $(-0.007, \mathrm{SE}=$ 0.006). However, there were statistically significant differences in yearly changes for weight and BMI, with steeper 
Table 6. Comparison of final height, weight, and BMI of ELBW and NBW young adult/parent dyads

\begin{tabular}{|c|c|c|c|c|c|}
\hline & \multicolumn{2}{|c|}{ ELBW $(n=116)$} & \multicolumn{2}{|c|}{ NBW $(n=103)$} & $p$ Value \\
\hline Height, mean (SD) & $164.0(9.5)$ & $170.3(5.2)$ & $170.9(10.4)$ & $170.6(5.9)$ & $<0.001$ \\
\hline BMI, mean (SD) & $24.3(6.3)$ & $25.7(3.5)$ & $25.0(6.4)$ & $25.2(2.7)$ & 0.16 \\
\hline
\end{tabular}

$\ddagger$ Repeated measures ANOVA.

Table 7. Hierarchical regression model for correlates of height z-scores for ELBW and NBW young adults

\begin{tabular}{|c|c|c|c|c|c|}
\hline Variables & $\frac{\text { Step } 1}{\text { Beta (SE) } p}$ & $\frac{\text { Step } 2}{\text { Beta }(\mathrm{SE}) p}$ & $\frac{\text { Step } 3}{\text { Beta }(\mathrm{SE}) p}$ & $\frac{\text { Step } 4}{\text { Beta }(\mathrm{SE}) p}$ & $\frac{\text { Step } 5}{\text { Beta (SE) } p}$ \\
\hline Gender & $\begin{array}{c}-0.138(0.145) \\
p=0.34\end{array}$ & $\begin{array}{c}-0.130(0.129) \\
p=0.31\end{array}$ & $\begin{array}{l}-0.135(0.129) \\
p=0.29\end{array}$ & $\begin{array}{c}-1.53(0.128) \\
p=0.23\end{array}$ & $\begin{array}{c}-0.141(0.127) \\
p=0.26\end{array}$ \\
\hline SESII (age 8 y) & $\begin{array}{c}-0.025(0.075) \\
p=0.73\end{array}$ & $\begin{array}{c}0.022(0.067) \\
p=0.74\end{array}$ & $\begin{array}{l}0.018(0.067) \\
p=0.78\end{array}$ & $\begin{array}{c}-0.0004(0.067) \\
p=0.99\end{array}$ & $\begin{array}{c}0.003(0.066) \\
p=0.96\end{array}$ \\
\hline SGA (16) & & & $\begin{array}{c}-0.211(0.197) \\
p=0.28\end{array}$ & $\begin{array}{c}-0.332(0.200) \\
p=0.09\end{array}$ & $\begin{array}{c}-0.338(0.199) \\
p=0.09\end{array}$ \\
\hline NSI & & & & $\begin{array}{c}-0.520(0.194) \\
p=0.008\end{array}$ & $\begin{array}{c}-0.439(0.199) \\
p=0.02\end{array}$ \\
\hline Chronic health (Teen) (6)§ & & & & & $\begin{array}{c}-0.074(0.004) \\
p=0.09\end{array}$ \\
\hline
\end{tabular}

Gender: males $=1$, females $=0 ;$ SGA: yes $=1$, no $=0 ;$ BW group:ELBW $=1, \mathrm{NBW}=0$; NSI: yes $=1$, no $=0$.

If Hollingshead 2-factor index at age $8 \mathrm{y}$.

$\S$ Chronic health conditions at teen (ELBW, $n=138$; NBW, $n=117$ ) include [ $n$ (\%)]: asthma [ELBW, 23 (17) vs NBW, 13 (11)], allergies [36 (26) vs 38 (32)], heart conditions [6 (4) vs 2 (2)], epilepsy [8 (6) vs 1 (1)], vision problems [79 (57) vs 23 (20)], hearing problems [8 (6) vs 6 (5)], recurrent bronchitis [7 (5) vs 3 (3)], kidney conditions [2 (1) vs 0 (0)], anemia [2 (1) vs 0 (0)].

growth for ELBW versus NBW participants $(0.039, \mathrm{SE}=$ $0.008 ; 0.051, \mathrm{SE}=0.009$ ).

\section{DISCUSSION}

Currently there is growing concern about disturbances in growth in utero and during the postnatal period, and their subsequent impact on long-term adult health. These concerns stem from the "fetal origins" hypothesis that undernutrition in utero at critical periods of development may "program" or induce permanent alterations in fetal metabolism, and make the individuals more susceptible to future derangements in cardiovascular and metabolic function (22). Although there is a paucity of studies designed specifically to investigate whether this hypothesis is also applicable to the premature infant (23-25), recent studies suggest that the association of low birth weight and cardiovascular and metabolic derangements are modified by postnatal factors, specifically, early growth failure (26), and subsequent accelerated increase in weight gain and BMI during adolescence and adulthood (2729). ELBW infants appear to be at double jeopardy: not only are they small at birth, but by the time they reach term equivalent age, the majority, even those who were appropriate for gestational age become SGA $(8,30)$. It appears that, despite recent advances in neonatal care, early growth failure is a continuing and worrisome problem for the current survivors $(1,3)$ that will likely impact on their subsequent long-term growth.
The McMaster study is a prospective population-based study of the largest cohort of ELBW survivors followed longitudinally to young adulthood, with growth data measured at six strategic ages after birth. Other strengths are inclusion of a reference group of NBW children, a high follow-up rate, and presentation of data by sex-specific z-scores that obviate any differences related to age and sex. However, the cohort was assembled by birth weight, and the bias of enrolling more mature infants who were SGA should be acknowledged; further, our NBW cohort was recruited at age $8 \mathrm{y}$, and thus we do not have measures at early childhood for comparison. Consistent with our hypothesis, we have shown that at YA, both male and female ELBW participants had significantly lower mean z-scores for weight and height, compared with their NBW counterparts, and all z-scores remained below zero. By this age, ELBW subjects have reached their maximum height potential, and it is unlikely that further increases will occur. Furthermore, the final height attainment of the ELBW cohort was significantly lower than their predicted mid-parental height. Although these differences in mean values of approximately $6-7 \mathrm{~kg}$ lighter and 6-7 $\mathrm{cm}$ shorter than the comparison group are substantial statistically, they should not be of major concern, as the ELBW YA still fall within the lower range of normal. Also, in light of recent concerns with regard to the metabolic and cardiovascular sequelae related to rapid weight gain and obesity (27-29), the effect of smallness, particularly in weight, may indeed be beneficial. ELBW sub- 
jects who were SGA had lower growth parameters at adulthood, but these did not achieve statistical significance. Exclusion of YA with NSI did not alter the findings of lower growth among ELBW participants.

In contrast, an Australian study of 42 ELBW subjects showed that, at age $20 \mathrm{y}$, the mean weight $\mathrm{z}$-score was not significantly lower than zero (10); however, although the height z-score was still significantly lower than zero, it was consistent with parental height. Hack et al. (8) reported a significant catch-up in both weight and height mean z-scores among VLBW females at age $20 \mathrm{y}$, but not among males, who remained significantly shorter and lighter than their NBW peers. A significant relationship was noted between maternal height and that of both cohorts of YA. In another Swedish study (7), VLBW boys at age $19 \mathrm{y}$, measured at the time of conscription to the army, were found to be shorter and lighter than other same-age recruits born at term. Similarly, the shorter self-reported stature of a British VLBW cohort at age 12 y (4) persisted to adulthood, particularly among females (9).

The phenomenon of catch-up growth in premature infants is interesting in terms of both timing and sex differences. Hack (8) reported that the already-growth-compromised VLBW infants at birth exhibited further decrease in weight $\mathrm{z}$-scores around term corrected age, and it was not until mid-childhood that significant catch-up growth commenced. An even greater catch-up in weight z-scores occurred between age 8 and $20 \mathrm{y}$ in VLBW females, such that they were now comparable to their NBW peers; this was not matched by a similar increase in height z-scores for either sex. We have similarly shown a substantial fall in mean weight z-scores between birth and $1 \mathrm{y}$, which was more marked for male ELBW infants. This was followed by a gradual increase to age $8 \mathrm{y}$, by which time both sexes were comparable. The largest increment in weight $\mathrm{z}$ scores occurred in ELBW females between age 8 and adolescence (6); however, by adulthood the rate of growth for height and weight had leveled off and both sexes of ELBW remained substantially lower than the NBW group. Doyle et al. (10) also showed a larger increase in weight z-scores for ELBW subjects between age 8 and $14 \mathrm{y}$, and no further changes between 14 and $20 \mathrm{y}$ of age (not analyzed by sex). These increases in growth between age 8 and adolescence reported in every study may be a reflection of the onset of puberty. We concur with the findings by Doyle et al. (10) that body size at adolescence is a good reflection of final adult attainment.

BMI, an index of proportionality, revealed continuing catch-up in z-scores and rapid crossing of percentiles between age 8 and adolescence, particularly for ELBW females in our study. Although height more than weight z-scores, were significantly lower than zero for both sexes, normalization of BMI z-scores at adulthood indicates that they are proportionate, and not overweight for their height. A similar pattern for mean BMI z-scores that were not significantly different from zero was reported by Doyle et al. (10) for ELBW YA. Hack et al. (8) reported a significantly greater female than male increase in BMI z-scores for VLBW between age 8 and $20 \mathrm{y}$ (of 0.58 versus $0.02, p<0.001$ ); the final mean BMI z-scores for VLBW and NBW females were comparable, whereas VLBW males remained significantly lower. Although catch-up rate for BMI among the premature group was greater among females in our study and that by Hack (8), rates of obesity were not different from NBW females. Interestingly, the mean BMI z-score of Swedish boys (7) was lower than their North American counterparts-BMI 21.2 (7) versus 22.9 (8) and 24.2 in the current study. However, we recognize the limitations of BMI as a measure of body composition and recommend DXA studies for a more accurate account of fat mass and lean mass index.

Unlike some investigators $(2,4)$, we found no differences in parental height and weight between the ELBW and NBW participants. We found that mid-parental height, social class, and sex of the young adult accounted for $21.3 \%$, or almost half of the total variance explained for height by the full model (40.1\%). Birth weight group explained a further $16.4 \%$ of the variance; other than NSI, there was no significant improvement in variance explained by the additional steps. The model explained only a small proportion of the variance for weight and BMI z-scores.

\section{CONCLUSIONS}

At adulthood, body size of both sexes of ELBW participants was significantly smaller in both height and weight compared with their peers, but normalization of BMI is indicative of proportionate growth parameters. Growth trajectories of ELBW infants followed a statistically significantly different pattern than the NBW group for weight and BMI (but not for height), and are consistent with the findings reported by others $(8,10)$, of relative undernutrition in infancy and rapid acceleration of growth during late childhood and adolescence-a pattern that may increase the risk for insulin resistance $(23,27,29)$ and coronary heart disease in later life $(24,25,28)$. Further follow-up is warranted to determine whether the rapid catch-up in growth at adolescence will predispose these subjects to have a higher prevalence of obesity at middle-age, which may further increase the risk for hypertension and cardiovascular disease. Despite a greater emphasis on improved nutrition in the neonatal intensive care units and postdischarge, current extremely immature survivors continue to be significantly smaller in their growth $(1,3)$. Our findings may have relevance for the future growth of these children.

Acknowledgments. The authors thank the ELBW and NBW young adults and their parents for their cooperation with our many studies. We also thank our research staff, Liz Merz (for tracing the subjects), Lorraine Hoult and Mary Lou Schmuck (for statistical analysis), Diane Turcotte (for typing the manuscript), and Dr. Stephanie Atkinson for her advice. We appreciate the support of the department of Pediatrics and the Children's Hospital, McMaster University, Hamilton, ON, Canada.

\section{REFERENCES}

1. Finnstrom O, Otterblad Olausson P, Sedin G, Serenius F, Svenningsen N, Thiringer K, Tunell R, Wesstrom G 1998 Neurosensory outcome and growth at three years in extremely low birthweight infants: follow-up results from the Swedish national prospective study. Acta Paediatr 87:1055-1060 
2. Hack M, Weissman B, Borawski-Clark E 1996 Catch-up growth during childhood among very low birthweight children. Arch Pediatr Adolesc Med 150:1122-1129

3. Wood NS, Costeloe K, Gibson AT, Hennessy EM, Marlow N, Wilkinson AR EPICure Study Group 2003 The EPICure study: growth and associated problems in children born at 25 weeks of gestational age or less. Arch Dis Child Fetal Neonatal Ed 88:F492-F500.

4. Powls A, Botting N, Cooke RW, Pilling D, Marlow N 1996 Growth impairment in very low birthweight children at 12 years: correlation with perinatal and outcome variables. Arch Dis Child Fetal Neonatal Ed 75:F152-F157

5. Ford GW, Doyle LW, Davis NM, Callanan C 2000 Very low birth weight and growth into adolescence. Arch Pediatr Adolesc Med 154:778-784

6. Saigal S, Stoskopf BL, Streiner DL, Burrows E 2001 Physical growth and current health status of infants who were of extremely low birth weight and controls at adolescence. Pediatrics 108:407-415

7. Ericson A, Källen B 1998 Very low birthweight boys at the age of 19. Arch Dis Child Fetal Neonatal Ed 78:F171-F174

8. Hack M, Schluchter M, Cartar L, Rahman M, Cuttler L, Borawski E 2003 Growth of very low birth weight infants at age 20 years. Pediatrics 112:e30-e38

9. Cooke RW 2004 Health, lifestyle, and quality of life for young adults born very preterm. Arch Dis Child 89:201-206

10. Doyle LW, Faber B, Callanan C, Ford GW, Davis NM 2004 Extremely low birth weight and body size in early adulthood. Arch Dis Child 89:347-350

11. Saigal S, Rosenbaum P, Hattersley B, Milner R 1989 Decreased disability rate among 3-year-old survivors weighing 501 to 1000 grams at birth and born to residents of a geographically defined region from 1981 to 1984 compared with 1977 to 1980. J Pediatr 114:839-846

12. Hollingshead AS 1975 Four Factor Index of Social Status. Yale University, New Haven, CT

13. Saigal S, Szatmari P, Rosenbaum P, Campbell D, King S 1991 Cognitive abilities and school performance of extremely low birth weight children and matched term control children at age 8 years: a regional study. J Pediatr 118:751-760

14. Boyle MH, Offord DR, Hoffman HG, Catlin GP, Byles JA, Cadman DT, Crawford JW, Links PS, Rae-Grant NI, Szatmari P 1987 Ontario Child Health Study 1: methodology. Arch Gen Psychiatry 44:826-831

15. Ware JE, Kosinski M 2001 SF-36 Physical and Mental Health Summary Scales: A Manual for Users of Version 1, 2nd Ed. QualityMetric Inc, Lincoln, RI

16. Kramer MS16, Platt RW, Wen SW, Joseph KS, Allen A, Abrahamowicz M, Blondel B, Breart G for the Fetal/Infant Health Study Group of the Canadian Perinatal Surveillance System 2001 A new and improved population-based Canadian reference for birth weight for gestational age. Pediatrics 108:E35; www.pediatric.org/ $\mathrm{cig} /$ content/full/108/2/e35
17. Kuczmarski RJ, Ogden CL, Grummer-Strawn LM, Flegal KM, Guo SS, Wei R, Mei Z, Curtin LR, Roche AF, Johnson CL 2000 CDC growth charts: United States. Adv Data Jun 8:1-27

18. Nellhaus G 1968 Head circumference from birth to eighteen years. Practical composite international and interracial graphs. Pediatrics 41:106-114

19. Boyle MH, Willms JD 2001 Multilevel modeling of hierarchical data in developmental studies. J Child Psychol Psychiatry 42:141-162

20. Rasbash J, Browne W, Goldstein H, Yang M, Plewis I, Healy M, Woodhouse G, Draper D, Langford I, Lewis T 2000 A User's Guide to MlwiN, Version 2.1. Institute of Education, London

21. Holm S 1979 A simple sequentially rejective multiple test procedure. Scand J Statis 6:65-70

22. Barker DJ, Winter PD, Osmond C, Margetts B, Simmonds SJ 1989 Weight in infancy and death from ischaemic heart disease. Lancet 2:577-580

23. Fewtrell MS, Doherty C, Cole TJ, Stafford M, Hales CN, Lucas A 2000 Effects of size at birth, gestational age and early growth in preterm infants on glucose and insulin concentrations at 9-12 years. Diabetologia 43:714-717

24. Finken MJ, Inderson A, Van Montfoort N, Keijzer-Veen MG, Van Weert AW, Carfil N, Frolich M, Hille ET, Romijn JA, Dekker FW, Wit JM, on behalf of the Dutch POPS-19 Collaborative Study Group 2006 Lipid profile and carotid intima-media thickness in a prospective cohort of very preterm subjects at age 19 years: effects of early growth and current body composition. Pediatr Res 59:604-609

25. Irving RJ, Belton NR, Elton RA, Walker BR 2000 Adult cardiovascular risk factor in premature babies. Lancet 355:2135-2136

26. Singhal A, Fewtrell M, Cole TJ, Lucas A 2003 Low nutrient intake and early growth for later insulin resistance in adolescents born preterm. Lancet 361:1089-1097

27. Bhargava SK, Sachdev HS, Fall CH, Osmond C, Lakshmy R, Barker DJ, Biswas SK Ramji S, Prabhakaran D, Reddy KS 2004 Relation of serial changes in childhood body-mass index to impaired glucose tolerance in young adulthood. N Engl J Med 350:865-875

28. Eriksson JG, Forsen T, Tuomilehto J, Osmond C, Barker DJ 2001 Early growth and coronary heart disease in later life; longitudinal study. BMJ 322:949-953

29. Cianfarani S, Germani D, Branca F 1999 Low birthweight and adult insulin resistance: the "catch-up growth" hypothesis. Arch Dis Child Fetal Neonatal Ed 81:F71-F73

30. Ehrenkranz RA, Younes N, Lemons JA, Fanaroff AA, Donovan EF, Wright LL, Katsikiotis V, Tyson JE, Oh W, Shankaran S, Bauer CR, Korones SB, Stoll BJ, Stevenson DK, Papile LA 1999 Longitudinal growth of hospitalized very low-birthweight infants. Pediatrics 104:280-289 